\title{
Modeling of IVR and Sensitivity Analysis of Cavity Injection System of a 1000MWe Advanced PWR
}

\author{
Muhammad Usman ${ }^{1 \mathrm{a}}$, Abdul Rehman Abbasi ${ }^{1 \mathrm{~b}}$, Naveed Ahmed ${ }^{2}$, Talha Shakoor ${ }^{1 \mathrm{c}}$
}

RECEIVED ON 26.03.2020, ACCEPTED ON 05.05.2021

\begin{abstract}
In-Vessel Retention (IVR) is one of the primary technique to mitigate severe accidents. This enables retaining the corium inside the Reactor Pressure Vessel (RPV) through external cooling. However, it is important to assess the validity and success of this technique, though actual validation is impossible. In this work, we have developed a model of selected case study and used MATLAB $2018 \mathrm{~b}$ to simulate it. Developed model has been tested using two sources; constant temperature source and constant heat flux. These two sources were applied at the internal surface of RPV separately and heat transfer through RPV lower plenum was monitored. Main purpose of this analysis is to obtain temperature profiles along the RPV lower plenum external surface. Results show that the technique is successful because external surface temperature is lower than melting point of RPV in both the cases discussed. Sensitivity analysis showed that external temperature can be further decreased by increasing heat transfer, which can be changed by thickness of RPV and sub-cooling of inlet water. However, both parameters have their own limitations. Results obtained through MATLAB simulations are also comparable to MELCOR1.8.5 code simulation results and both found in agreement.
\end{abstract}

Keywords: In-Vessel Retention, Severe Accident, External Vessel Cooling, Water Injection, PWR

\section{INTRODUCTION}

$\mathrm{N}$ uclear reactors are becoming viable source of electricity because of their economics and load following capabilities that are being continuously assessed for emerging energy mix scenarios including renewables [1]. However, it is imperative to design them safely to mitigate severe accident conditions such as the Fukushima. Severe accident pose risk of radioactivity exposure to the environment. So to make them acceptable for public, research has to be performed to design reactors inherently safe and capable of mitigating severe accidents.

After TMI-2 accident, external vessel cooling along with RPV insulation was first studied by Henry and Fauske [2]. They proposed that, after a severe accident, injection in Reactor Coolant System (RCS) may not be possible but there must be enough water in containment to submerge RPV for external cooling. So, heat transfer evaluation of two phase flow from external cooling of RPV was performed.

The IVR is the technique used to mitigate severe accidents at Nuclear Power Plant (NPP) [3]. In case of accident, Thoefanous and Syri [4] discussed the coolability limitations of RPV lower plenum, during corium retention. In their technique corium (molten mixture of fuel, clad and core supporting materials) is retained inside the RPV through external cooling of RPV. A flow path is established between RPV external surface and insulation of RPV with minimal hindrance in flow of cooling water. In fact, the IVR technique which was actually originated from Generation-II reactors (e.g. VVER-440 and CNP-300 etc.) in order to cope up core-melt risk, is now extensively recommended and adopted for the new deigns of

${ }^{1}$ Karachi Institute of Power Engineering College, Pakistan Institute of Engineering and Applied Sciences, Karachi, Sindh, Pakistan.

Email: am.usman1005@gmail.com, barehman.abbasi@kinpoe.edu.pk (Corresponding Author), 'talhashakoor94@gmail.com

${ }^{2}$ Safety Analysis Centre, Pakistan Nuclear Regulatory Authority. Email: naveed.ahmed@ pnra.org

This is an open access article published by Mehran University of Engineering and Technology, Jamshoro under CC BY 4.0 International License. 
Generation-III reactors such as Westinghouse AP1000, the Korean APR1400 as well as Chinese advanced PWR designs HPR1000 and CAP1400 [5].

IVR was first adopted in AP600 and improved but this reactor was not commercialized. Research showed that the technique is feasible for large power reactors as well. Purpose of that research was to validate IVR phenomenon and provide experimental data [6]. Later on, that plant design was extended to AP1000 and APR1400.

APR-1400 was analyzed using SCDAP/RELAP5-3D severe accident code [7]. Purpose of this analysis was to analyze late-melt configurations that can affect IVR. So that, results can be used to improve design of core catcher and enhance external vessel cooling for corium retention. Results showed that relocation starts earlier if LBLOCA occurs on the cold leg, it causes increase in heat flux due to large power retained in melt and yield maximum thermal loading on RPV lower plenum. It also requires core catcher to make IVR feasible in this case. Surge line of pressurizer may fail due to creep and it favors IVR because fast cooling will occur and it will delay melt relocation.

\section{LITERATURE REVIEW}

Purpose of corium retention is to avoid ex-vessel phenomena; concrete corium interactions, hydrogen detonation, steam explosion (corium and water interaction), containment pressurization and heating, containment leakage or bypass and basement penetration.

\subsection{IVR Analysis and Validation}

To analyze and validate IVR technique, some parameters are studied and analyzed by changing some independent variables e.g. changing geometry of RPV, flow of cooling water, corium configurations by changing thickness of light metal layer or changing $\mathrm{UO}_{2}$ fraction in oxide pool etc. These parameters are heat flux and temperature, calculated at external surface of RPV. Calculation is performed for different types of accidents like in this case the Large Break Loss of Coolant Accident (LBLOCA) is selected to verify success of IVR. Then success criteria are defined, for critical heat flux external wall flux should be less than critical heat flux.

Before analysis of corium retention, first we have to study the corium settling in RPV lower plenum. On complete melt down, corium temperature is very high and radiation heat transfer from upper layer may melt other RPV internal core supporting materials (including reflector, upper plenum structures and core barrel) forming molten layers depending upon their densities [8].

Two type of molten pool models are considered during analysis: two-layer model (simplified) and illustrated three-layer model. In three-layer model, upper layer is made of light metals ( $\mathrm{Fe}, \mathrm{Zr}$ ), second layer is of oxides $\left(\mathrm{UO}_{2}+\mathrm{ZrO}_{2}\right.$ etc. $)$ and third and final layer contains heavy metals (like dissolved Uranium in un-oxidized Zircaloy etc.). In two-layer model heavy metal layer is neglected to simplify the analysis. Corium configuration on complete melt-down is shown in Fig.1.

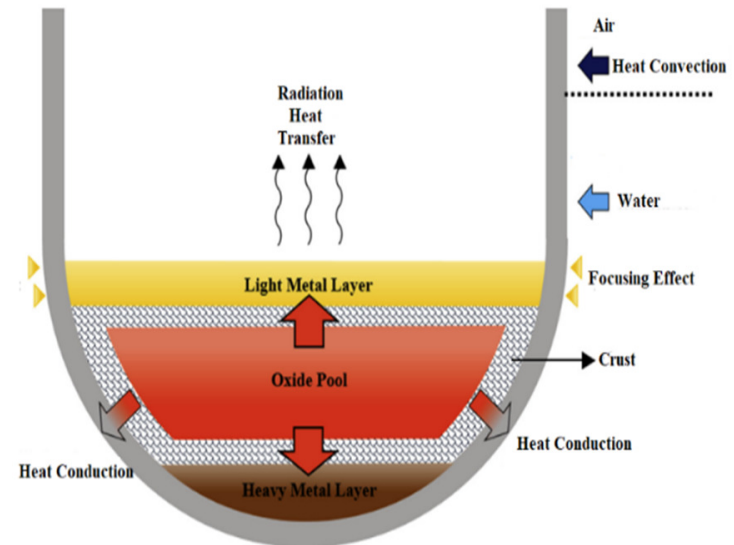

Fig.1: Three-layered core melt phenomenon [7]

Light metal layer has high conductivity and affects magnitude of heat flux considerably. On reduction in metallic layer excess heat remaining after radiation, coming from oxide layer, is focused to RPV sidewalls, known as Focusing Effect [9]. So, the chance of penetration is large in focusing region.

To validate IVR, research has been conducted including statistical, numerical and experimental techniques. Studies show that in this technique, water is present at the external surface of the RPV and boils away as it reaches its saturation temperature and it is 
replaced by water having lower temperature. In this way external surface temperature remains close to the saturation temperature of water.

\subsubsection{Critical Heat Flux Calculation}

A probabilistic analysis of Passive Cavity Injection System (PCIS) for Chinese improved 1000MWe PWR was performed using Risk Oriented Accident Analysis Methodology (ROAAM) [10]. IVR assessment code was developed in MATLAB. Heat flux was calculated using probabilities and values of decay power, zirconium oxide fraction and mass of stainless steel and then compared with critical heat flux using critical heat flux correlation developed using experimental data from ULPU (a IVR related boiling heat transfer facility at University of California, Santa Barbara) experiment for natural convection due to buoyancy force. Calculated probability of success for cavity injection system was $98.1 \%$.

To calculate safety margin of in-vessel retention for AP1000 [11], analysis was conducted by developing a code called IVR Analysis code in Severe Accidents (IVRASA). Code was executed for both corium configurations to calculate heat flux. Results showed that external heat flux was lower than critical heat flux. Sensitivity analysis for different values of uranium fraction, showed that RPV may fail due to Focusing Effect when metal layer is thin.

In [12], the authors provided formulation of onedimensional analysis for both two-layer and threelayer configurations for AP1000 and evaluated the critical heat flux. Results showed that flux is lower than critical heat flux in oxide region but may increase in focusing region. They also calculated the probability of RPV failure due to focusing effect; the value is about $0.04-0.3$.

Heat flux at inner and outer surface of RPV under IVR was evaluated using birth-and-death technique in ANSYS Mechanics 14.5 [13]. APR-1400's RPV was modelled and flux was evaluated. Sensitivity analysis showed that increase in corium emissivity (0.4) increases heat flux at cylindrical region of RPV in focusing region, heat flux decreases by $10 \%$ after using two-dimensional conduction in RPV wall instead of one-dimensional heat conduction providing extra thermal margin. Analysis also showed that heat flux is strongly affected by corium pool formation.

Experimental studies performed on RPV wall to calculate critical heat flux and to determine the effect of sub-cooling and impurity [14]. Tri-sodium phosphate $\left(\mathrm{Na}_{3} \mathrm{PO}_{4}\right)$ was added to cooling water to change water boiling temperature and to increase heat transfer. Adding impurity ( $\left.5000 \mathrm{ppm} \mathrm{Na}_{3} \mathrm{PO}_{4}\right)$ to cooling water showed increase in critical heat flux. Increase of critical heat flux, will increase the margin towards safety. Because when RPV external wall heat flux increases from critical heat flux boiling crisis occurs and a large temperature transition occurs which causes RPV melt-down.

In [15], the authors developed different MELCOR models for large scale PWR with thermal power reaching $5000 \mathrm{MWt}$ and performed In- and ex-vessel coupled transient analysis of IVR-ERVC (External Reactor Vessel Cooling) phenomenon which was reportedly found to be an effective strategy to maintain RPV integrity.

\subsubsection{Temperature Calculation}

In previous studies IVR success was analyzed by the criterion that external heat flux should remain lower than the critical heat flux. But in this study, IVR success is analyzed by RPV external temperature, to analyze whether external temperature is less or greater than RPV melting point. RPV external surface temperature is calculated using two different methodologies:

a) Conservative approach: Application of post reactor scram decay heat (taken from LBLOCA scenario without any mitigation case) directly to the RPV lower head inner surface as an internal heat source.

b) Less conservative approach: Application of constant temperature source (of corium at the time of melting) at the inner surface of lower head.

Heat transfer analysis is performed in MATLAB 2018b. Temperature profiles are calculated by MATLAB code and compared with the profiles obtained from MELCOR 1.8.5 severe accident analysis code with external vessel cooling system.

Mehran University Research Journal of Engineering and Technology, Vol. 41, No. 1, January 2022 [p-ISSN: 0254-7821, e-ISSN: 2413-7219] 


\section{DESCRIPTION OF CASE STUDY}

A generation III advanced Pressurized Water Reactor (PWR) of $1000 \mathrm{MWe}$ is selected to study IVR. This reactor has been equipped with severe accident mitigation measures; double containment, cavity injection and cooling system, dedicated depressurization system and containment hydrogen combination system. Reactor Cavity Injection and Cooling System (CIS) is used to cool RPV externally in case of severe accident. Parameters of CIS are given in Table 1.

\begin{tabular}{|c|c|c|}
\hline \multicolumn{3}{|c|}{$\begin{array}{c}\text { Table1: Cavity Injection System Design } \\
\text { Parameters }\end{array}$} \\
\hline S.No. & Parameter Name & $\begin{array}{l}\text { Parameter } \\
\text { Value }\end{array}$ \\
\hline 1 & $\begin{array}{l}\text { Passive System Flow } \\
\text { Rate }\end{array}$ & $70 \mathrm{~m}^{3} / \mathrm{h}$ \\
\hline 2 & $\begin{array}{l}\text { Active Systme Flow } \\
\text { Rate }\end{array}$ & $900 \mathrm{~m}^{3} / \mathrm{h}$ \\
\hline 3 & IRWST Volume & $2403 \mathrm{~m}^{3}$ \\
\hline 4 & IRWST Temperature & $15-55^{\circ} \mathrm{C}$ \\
\hline 5 & $\begin{array}{l}\text { CIS Passive Tank } \\
\text { Volume }\end{array}$ & $2281 \mathrm{~m}^{3}$ \\
\hline
\end{tabular}

Dedicated depressurization system is essential for CIS to work properly otherwise high melt ejection occurs because of high pressure in RPV. In case of severe accident, RPV fast depressurization is required using dedicated valves designed for the purpose. Normally, CIS is isolated completely and only used in Design Extension Conditions (DEC) i.e. those circumstances in which significant core melt occurs and it is required to retain this corium in RPV to avoid radioactivity from coming out after compromising first two barriers of safety. First event after the severe accident is core uncovering. Heat accumulates in RPV because of coolant loss which leads to core melt down. The purpose of external cooling is to remove that heat and protect RPV from failure. MELCOR analysis for large PWR of 1500 MWe showed that it is necessary to inject water before the start of the melt-down of core [16]. Therefore, RPV bottom should be submerged in water before the start of core melt down.

RPV is insulated externally to avoid heat loss and a channel is formed between RPV and insulation. That channel is used to inject water to cool RPV externally. Water and steam comes out near RPV outlets to containment. Active system of CIS, injects water in that channel from In-Containment Refueling Water Storage Tank (IRWST) and water enters from bottom of RPV all the way up to specific height of RPV and collected in IRWST, also working as a sump for recirculation. Passive system injects water using gravitational pull, water is stored in passive tank at high altitude as compared to RPV. Schematic diagram of CIS is shown in Fig. 2.

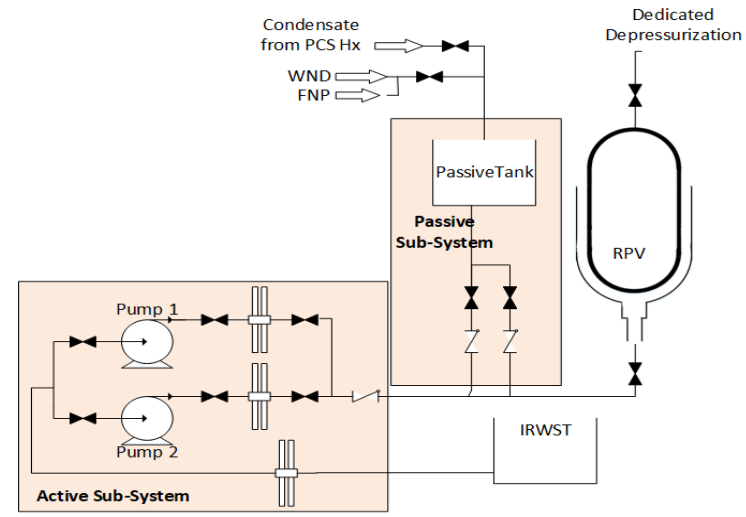

Fig. 2: Schematic diagram of CIS

The IRWST is also used as a water source for safety injection. It has high concentration of boric acid up to 2300ppm. CIS is designed for that value of boric acid concentration. CIS actuation is performed manually by the operator. CIS pumps are started at mini flow when core exit temperature reaches $600^{\circ} \mathrm{C}$ and when core external temperature reaches $650^{\circ} \mathrm{C}$ pump outlet valves are opened and rated flow is developed. If active system fails to operate the water injection is performed by passive system, actuated by dc battery source capable to provide power up to $72 \mathrm{hr}$. To control temperature and pressure of containment Passive Containment Spray (PCS) system is also designed and water is collected in IRWST or in passive system tank for active or passive system respectively. CIS cooling water temperature is selected $45^{\circ} \mathrm{C}\left(318^{0} \mathrm{~K}\right)$ because IRWST is located inside the containment.

\section{NUMERICAL FORMULATION}

Heat of corium pool is transferred to external surface of RPV through conduction then it is being removed 
by forced convection or buoyancy convection depending upon the working of active or passive subsystem of cavity injection system. Numerical expressions governing conduction heat transfer in 2D and convection heat transfer are given in Equation (1) and (2) respectively.

$\frac{\partial \mathrm{T}}{\partial \mathrm{t}}-\frac{\mathrm{k}}{\rho \mathrm{c}} \nabla^{2} \mathrm{~T}=0$

where $\mathrm{k}, \mathrm{c}$ and $\rho$ are thermal conductivity, specific heat, density of RPV material (16Mn5D).

$\mathrm{Q}_{\text {ext }}{ }^{\prime \prime}=\mathrm{h} \Delta \mathrm{T}$

where $\mathrm{h}$ and $\mathrm{Q}_{\text {ext }}$ " are convection heat transfer coefficient and heat flux at external surface of RPV, respectively.

\section{SYSTEM MODELING}

To analyze cavity injection and cooling system, modeling is performed in MATLAB 2018b. RPV geometry is modelled in PDE Toolbox where MATLAB code is developed. RPV parameters required to model the geometry are given in Table 2 .

The objective of this analysis is to calculate the temperature profile of external surface of RPV, lower spherical part is the area where penetration may occur. Only lower plenum of RPV is under consideration, there is no need to model full RPV geometry. In this study, only right half of RPV lower plenum is modelled to make the model simpler and easy to analize. If full RPV geometry is modelled its analysis will take more time, memory and it will also limit

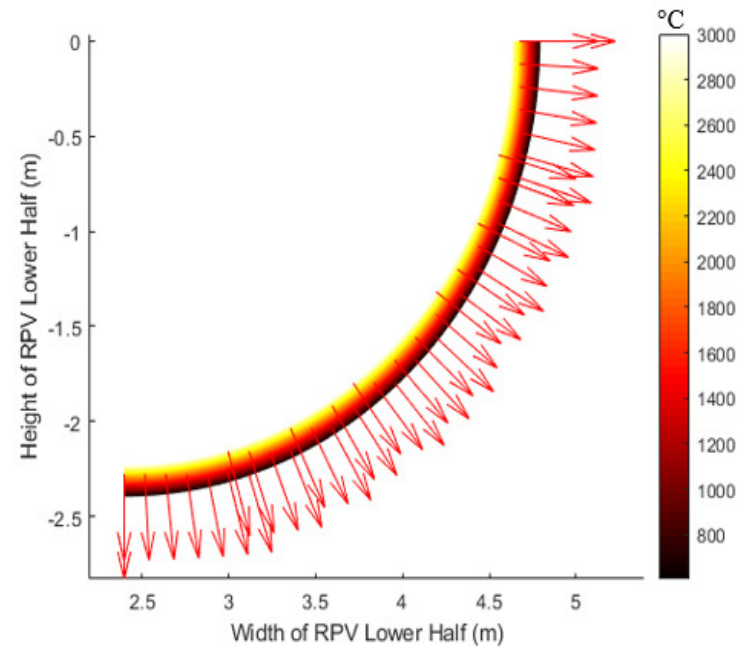

meshing size of the model. In this case, mesh size of $10 \mathrm{~mm}$ is selected with triangular mesh geometry, it is max length of triangle's side. Now, heat source is applied at lower plenum internal surface. In this case, analysis is performed by using two types of heat sources; constant temperature and constant heat flux.

\begin{tabular}{|c|c|c|}
\hline \multicolumn{3}{|c|}{ TABLE 2: RAECTOR PRESSURE VESSEL PARAMETERS } \\
\hline S.No. & Parameter Name & Parameter Value \\
\hline 1 & $\begin{array}{c}\text { Thickness of RPV } \\
\text { Lower Head }\end{array}$ & $168 \mathrm{~mm}$ \\
\hline 2 & Shape of Lower Head & Spherical \\
\hline 3 & $\begin{array}{c}\text { Outer Radius of } \\
\text { Sherical Part }\end{array}$ & $2.397 \mathrm{~m}$ \\
\hline 4 & $\begin{array}{c}\text { Height of RPV } \\
\text { Insulation }\end{array}$ & $7.995 \mathrm{~m}$ \\
\hline 5 & Water Height in RPV & $4.0 \mathrm{~m}$ \\
\hline
\end{tabular}

\subsection{Case A: With Constant Temperature Source}

In the first case, constant temperature source is selected by the fact that on clad and fuel melt their temperature is approximately $3000^{\circ} \mathrm{C}$. So, corium of that temperature will be in direct contact to RPV lower plenum and can be used as the heating source for analysis of CIS. During simulation of model a constant temperature source is modelled at the inner surface of the RPV and convection heat transfer is performed by defining the external surface as convective heat transfer boundary. Heat flow from RPV internal surface to external surface is shown on left hand side in Fig. 3.

Fig. 3: Heat flow with temperature gradient for both configurations

(Left) with constant temperature source (Right) with constant heat flux source. 


\subsection{Case B: With Constant Heat Flux Source}

In the second case, constant heat flux is applied at the inner surface of RPV lower plenum. On core melt down corium is collected at the bottom of RPV. Decay heat, produced on reactor scram is needed to be removed. A severe accident is selected as combination of LBLOCA, Station Blackout (SBO) and Total Loss of Feed Water (TLOFW) with no Safety Injection (SI). Decay heat profile obtained after simulating the accident is shown in Fig. 4.

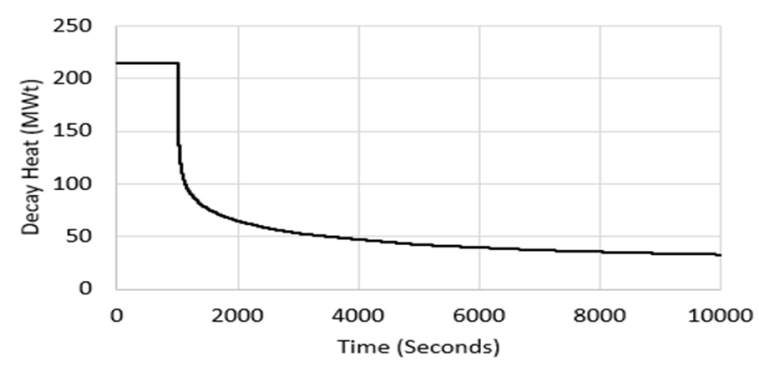

Fig. 4: Decay heat profile obtained after LBLOCA, SBO, TLFW and no SI

Constant heat flux is calculated by dividing decay heat and surface area of RPV. That heat flux is applied at the inner surface of RPV and external surface is defined as convective heat transfer boundary. Heat flow from internal to external surface for case B is on right hand side in Fig. 3.

Following assumptions are made before developing and simulating the model:

(i) No thinning of RPV lower plenum occurs i.e. temperature at the inner surface may exceed from the melting temperature of RPV and may become part of corium and that erosion of RPV occurs.

(ii) Water in IRWST is sufficient enough for 72hrs, because PCS is not modeled here so actual recirculation cannot be modelled.

\subsection{MELCORE Code Configuration Parameters}

All the time in which core material enters the lower head is taken as the time of molten pool formation, corresponding to the maximum decay heat time of molten pool. Initial conditions of severe accident sequence analysis are as follows: (i) The reactor power is equal to $100 \%$ of its nominal value.

(ii) The primary average temperature is equal to its nominal value at full power.

(iii) The pressurizer pressure is equal to its nominal value at full power.

(iv) The pressurizer water level is equal to its nominal value at full power.

(v) The SGs water level is equal to its nominal value at full power.

(vi) The reactor coolant flow rate is the best estimated flow rate.

\section{SIMULATION RESULTS}

After defining boundary conditions and simulating the model, external surface temperature of RPV lower plenum along the angle is obtained. Internal and External temperature profiles calculated using MATLAB code for case A and Case B are shown in Fig. 5 and 6 respectively. In constant temperature case, internal temperature of RPV is set at $3000^{\circ} \mathrm{C}$ and external temperature is $332^{\circ} \mathrm{C}$.

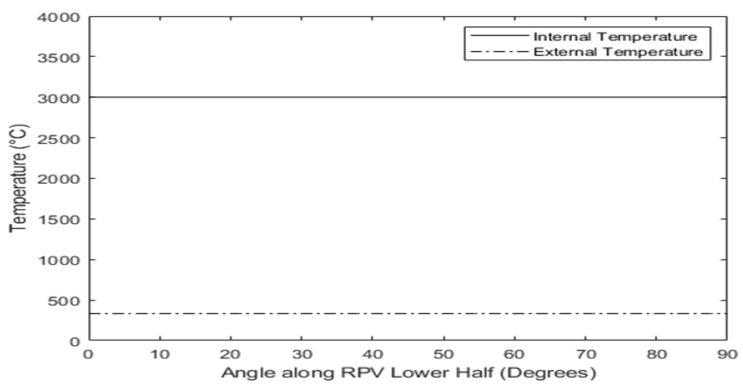

Fig. 5: Internal and external temperature profiles along RPV lower plenum for case A (Constant temperature source)

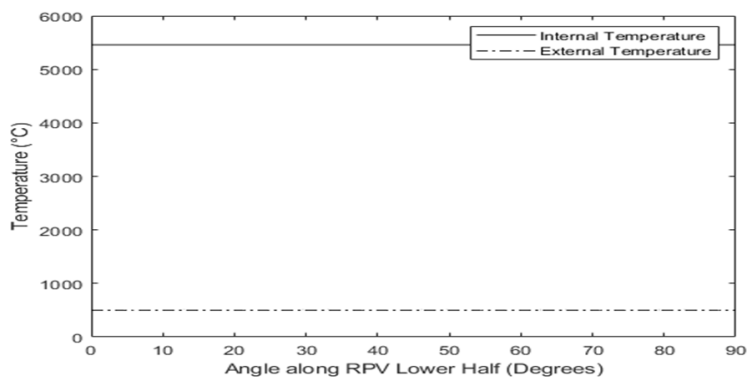

Fig. 6: Internal and external temperature profiles along RPV lower plenum for case B (Constant heat flux source) 
In constant heat flux case, internal temperature is $5500^{\circ} \mathrm{C}$ and external temperature is $500^{\circ} \mathrm{C}$. It may be noted that constant heat flux case is a conservative approach because in that case decay heat is directly applied at the internal surface of RPV without safety injection. Therefore, temperature for case $\mathrm{B}$ has higher value than case A. In both cases, external temperature is less than melting temperature of RPV (RPV grade is $16 \mathrm{Mn} 5 \mathrm{D}$ and melting temperature is 1700 Kelvin or $1627^{\circ} \mathrm{C}$ ), fulfilling the success criterion.

Temperature profiles calculated using MELCOR code for case A and Case B are shown in Fig. 7 and 8 respectively. In case of constant temperature source, internal nodes temperature is $2700^{\circ} \mathrm{C}$ (cooled down from $3000^{\circ} \mathrm{C}$ ), middle nodes temperature is $1500^{\circ} \mathrm{C}$ and external temperature is $150^{\circ} \mathrm{C}$.

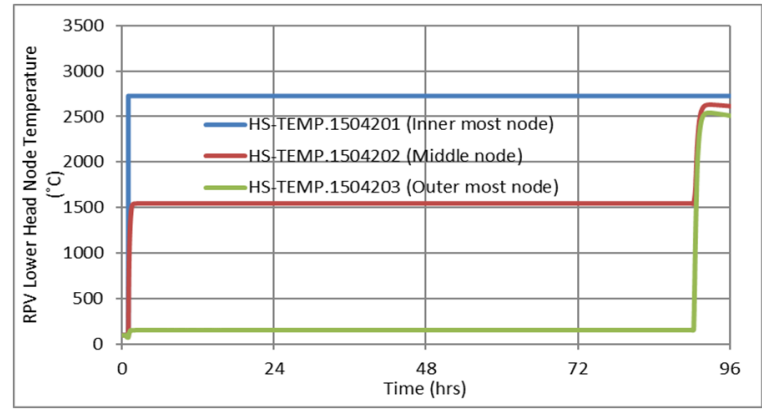

Fig. 7: MELCOR temperature profiles of internal, middle and external nodes for constant temperature sources

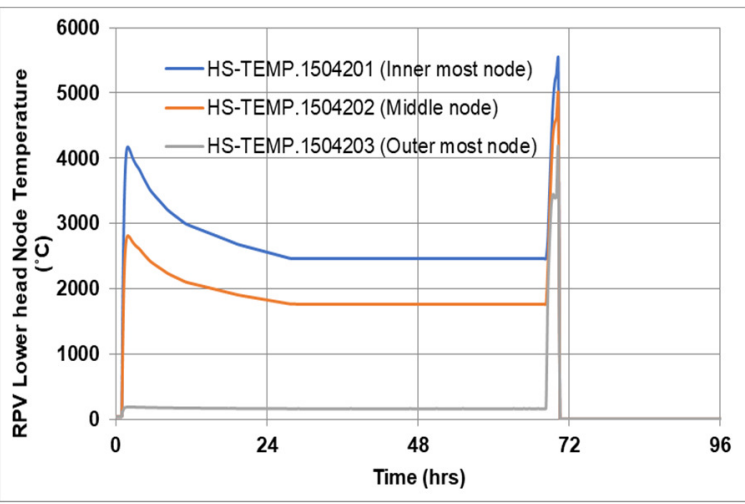

Fig. 8. MELCOR temperature profiles of internal, middle and external nodes for heat flux sources

In case of heat flux source, internal nodes temperature varies from $4100^{\circ} \mathrm{C}$ to $2700^{\circ} \mathrm{C}$ along the lower plenum of RPV, middle nodes temperature varies from $2900^{\circ} \mathrm{C}$ to $1850^{\circ} \mathrm{C}$ and external nodes temperature is approximately $150^{\circ} \mathrm{C}$.

In both cases, external temperature is lower than melting temperature. Internal and external temperatures obtained using MATLAB code are larger than the temperatures from MELCOR code but are in acceptable range. Difference of temperature values is due to the fact that in MELCOR analysis variable heat flux changes with time, but in MATLAB analysis heat flux is taken to be constant i.e. max value is taken to be more conservative.

\subsection{Sensitivity Analysis}

It is the analysis of a dependent variable with the change in independent variable or variables. In this analysis, two parameters are changed; RPV thickness and cooling water temperature for both case $\mathrm{A}$ and case $\mathrm{B}$ and their effect on external temperature is monitored.

\subsubsection{RPV Lower Plenum Thickness}

In first case, thickness of RPV lower plenum is changed from $163 \mathrm{~mm}$ to $178 \mathrm{~mm}$ with $5 \mathrm{~mm}$ thickness change. With increase in thickness, resistance to the flow of heat increases, as a result temperature at external surface decreases but this decrease also indicates that heat removal from the RPV will take more time as compared to lower thickness case. External temperature variation with the change in thickness of RPV lower plenum for constant temperature source and constant heat flux source are shown in Fig. 9 and 10 respectively.

For constant temperature source external temperatures are $307^{\circ} \mathrm{C}, 320^{\circ} \mathrm{C}, 332^{\circ} \mathrm{C}$ and $348^{\circ} \mathrm{C}$ for thickness values of $178 \mathrm{~mm}, 173 \mathrm{~mm}, 168 \mathrm{~mm}$ and $163 \mathrm{~mm}$ respectively.

In case of constant heat flux source, same trend in temperature for change in thickness of RPV lower plenum can be seen. External temperatures are $493.5^{\circ} \mathrm{C}, 497^{\circ} \mathrm{C}, 500.5^{\circ} \mathrm{C}$ and $503.9^{\circ} \mathrm{C}$ for thickness values of $178 \mathrm{~mm}, 173 \mathrm{~mm}, 168 \mathrm{~mm}$ and $163 \mathrm{~mm}$ respectively.

By decreasing the thickness of RPV lower plenum, 
heat transfer can be increased but thickness value of RPV has a limiting value depending upon the mechanical loading and pressurization in RPV which is calculated by mechanical stress and loading analysis, not the scope of this paper.

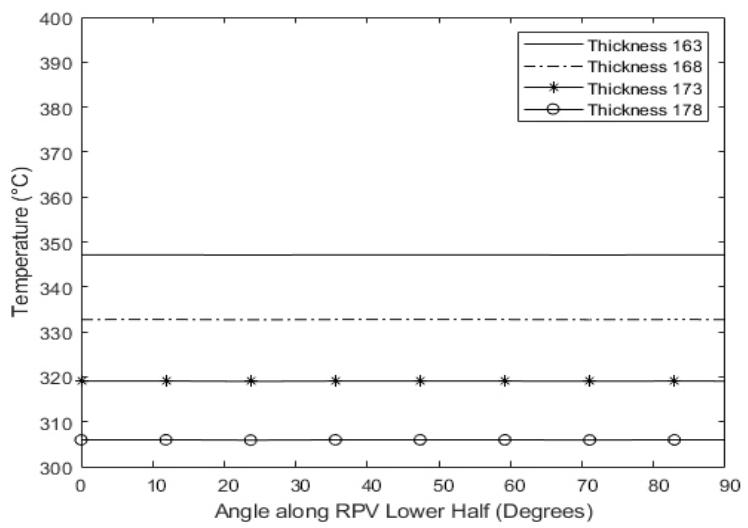

Fig. 9: External temperature variation by changing thickness of RPV lower plenum for constant temperature source

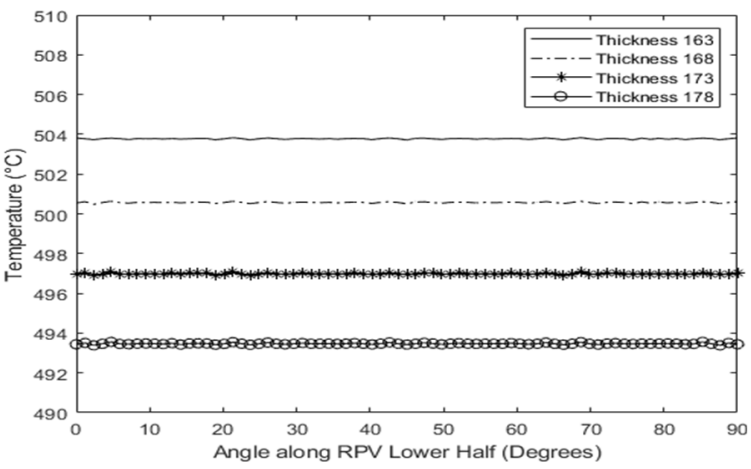

Fig. 10: External temperature variation with the change in thickness of RPV lower plenum for constant heat flux source

\subsubsection{Water Sub-Cooling}

In the second case, cooling water temperature is changed from $35^{\circ} \mathrm{C}$ to $65^{\circ} \mathrm{C}$ with $10^{\circ} \mathrm{C}$ margin. Heat transfer changes with change in cooling water temperature. With the decrease in cooling water temperature heat transfer increases due to increase in temperature gradient. Change of external temperatures with change in water sub-cooling for constant temperature source and constant heat flux source are shown in Fig. 11 and 12 respectively.

In case $\mathrm{A}, \mathrm{RPV}$ lower plenum external temperature changes from $324.9^{\circ} \mathrm{C}, 332.6^{\circ} \mathrm{C}, 341^{\circ} \mathrm{C}$ and $349^{\circ} \mathrm{C}$ for the change in water temperature from $35^{\circ} \mathrm{C}, 45^{\circ} \mathrm{C}$, $55^{\circ} \mathrm{C}$ and $65^{\circ} \mathrm{C}$ respectively.

In case $\mathrm{B}, \mathrm{RPV}$ lower plenum external temperature changes from $490.1^{\circ} \mathrm{C}, 500.1^{\circ} \mathrm{C}, 510.1^{\circ} \mathrm{C}$ and $520.1^{\circ} \mathrm{C}$ for the change in water temperature from $35^{\circ} \mathrm{C}, 45^{\circ} \mathrm{C}$, $55^{\circ} \mathrm{C}$ and $65^{\circ} \mathrm{C}$ respectively.

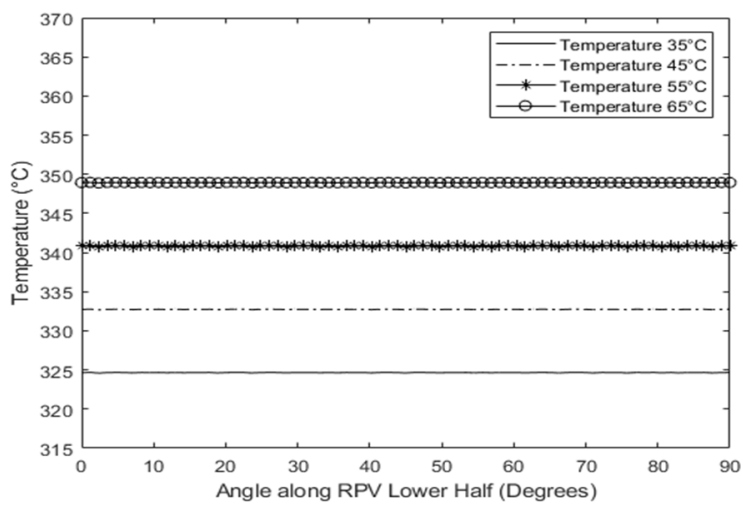

Fig. 11: External temperature variation with the change in temperature of cooling water for constant temperature source

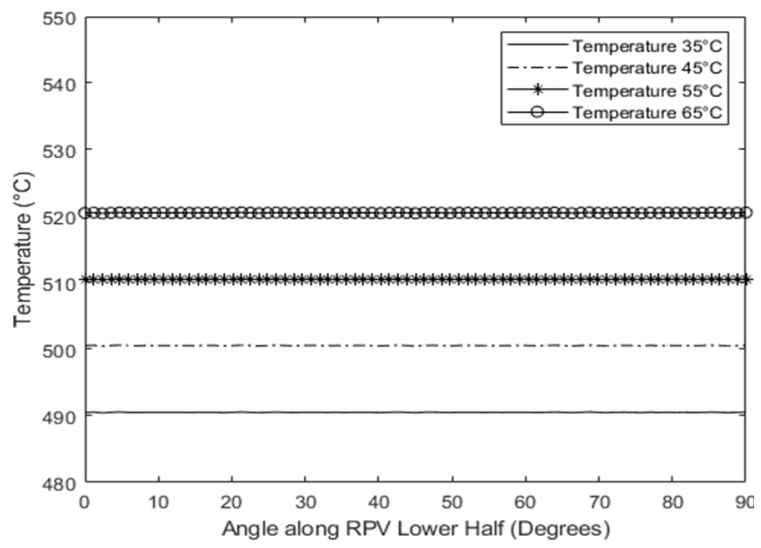

Fig. 12. External variation with the change in temperature of cooling water for constant heat flux source

Decrease in external temperature is due to its cooling by water of lower temperature i.e. increase in heat transfer. But the temperature value is limited due to the fact that water is drawn from IRWST which is located inside the containment, also on accident occurrence IRWST works as sump so all the water is collected in IRWST and its temperature increases. Analysis is performed for range of temperature values $\left(35^{\circ} \mathrm{C}\right.$ $65^{\circ} \mathrm{C}$ ), to analyze that on accident occurrence temperature of water increases. Results showed that 
RPV external temperature remains below the melting point in all temperature values discussed.

An important aspect of this analysis is extending the findings of European Union (EU) "Stress Tests" which are part of response in post-Fukushima scenario. Under these tests, findings indicate the concerns regarding IVR of VVER-1000 reactors [17]. Models tested and reported by [18-20] show that the uncertainties do exist with these models and a need of benchmarking on the computer codes does exist. In this regard, the results reported in this work does provide support to the argument of establishing benchmark especially when constant heat source and constant temperature source analysis are performed. Hence these results are comparable to the previously analyzed models with the addition of sensitivity analysis carried out to study the behavior of a dependent variable with independent variables.

\section{CONCLUSION}

In-vessel retention is a technique adopted to retain corium inside the reactor pressure vessel. For a 1000 MWe advance reactor, heat transfer analysis to calculate RPV lower plenum external surface temperature was performed, Cavity Injection and Cooling System is a system designed for RPV external cooling. Analysis was performed to validate the technique whether it is capable to retain corium inside RPV, using two different heat sources; constant temperature source and constant heat flux applied at the inner surface of the RPV lower plenum. External cooling was performed by water in case of active system availability and by natural convection (passive system) in case of active system failure. External temperature at the outer surface of RPV is lower than the melting point of RPV (1700Kelvin). Results show that IVR is a successful technique to protect RPV from failure.

Sensitivity analysis was also performed by changing two independent variables and analyze their effect on dependent variable i.e. outer surface temperature of lower plenum of RPV. Temperature of outer surface decreases with lowering the inlet water temperature and by reducing the thickness of RPV. Cooling water temperature depends upon containment temperature because water is drawn from IRWST, which is located inside containment. Thickness value of RPV is also limited by the fact that if it is decreased considerably RPV will fail due to mechanical loading and stress. MELCOR and MATLAB results are the same, both state that external temperature is lower than the melting temperature of RPV. So, corium will be retained in RPV and it will not fail due to lower plenum melting. Results obtained show that approach is suitable in assessing the in-vessel retention technique.

In this work, analysis is performed using constant heat flux. In future, external temperature analysis can be extended for variable heat flux to make the analyses closer to real scenario.

\section{ACKNOWLEDGEMENT}

The authors are thankful to the support provided by Safety Analysis Centre of PNRA for provision of code for analysis.

\section{REFERENCES}

1. "Technical and Economic Aspects of Load Following with Nuclear Power Plants", Nuclear Energry Agency Report, OECD Publications, 2011.

2. Henry R. E., Fauske H. K., "External cooling of a reactor vessel under severe accident conditions", Nuclear Engineering and Design, Vol. 139, No.1, pp. 31-43, 1993.

3. Kymäläinen $\mathrm{O}$, Tuomisto H, Theofanous TG. "Invessel retention of corium at the Loviisa plant", Nuclear Engineering Design, Vol. 169, No. 1-3, pp. 109-30, 1997.

4. Theofanous T.G., Syri S., "The coolability limits of a reactor pressure vessel lower head", Proceedings of the $7^{\text {th }}$ International Meeting on Nuclear Reactor Thermal-Hydraulic Nureth-7, New York, USA, 1995.

5. Ma W., Yuan Y., Sehgal B. R., "In-vessel melt retention of pressurized water reactors: historical review and future research needs", Engineering, Vol. 2, No.1, pp. 103-111, 2016

6. Knudson D. ., Rempe J. ., Condie K. ., Suh K. ., Cheung F.-B., Kim S.-B, "Late-phase melt conditions affecting the potential for in-vessel retention in high power reactors", Nuclear 
Engineering and Design, Vol. 230, No.1, pp. 133-150, 2004

7. Theofanous T.G., Oh S.J., Scobel J.H., "In-vessel retention technology development and use for advanced PWR designs in the USA and Korea", International Nuclear Energy Research Initiative, Project No. 2002-022-K (I), 2004.

8. Kim T.H., Kim S. H., Chang Y.-S. "Structural assessment of reactor pressure vessel under multilayered corium formation conditions", Nuclear Engineering and Technology, Vol. 47, No.3, pp. 351-361, 2015.

9. Wang X., Cheng X., "Analysis of focusing effect of light metallic layer in stratified molten pool under IVR-ERVC condition", Journal of Nuclear Engineering and Radiation Science, Vol.1, No.2, 2015.

10. Li Y. B., Tong L.L., Cao X. W., Guo D. Q., "Invessel retention coolability evaluation for Chinese improved 1000 MWe PWR", Annals of Nuclear Energy, Vol. 76, pp. 343-349, 2015.

11. Zhang Y. P., Qiu S. Z., Su G. H., Tian W. X., "Analysis of safety margin of in-vessel retention for AP1000", Nuclear Engineering and Design, Vol. 240, No. 8, pp. 2023-2033, 2010.

12. Esmaili H., Khatib-Rahbar M., "Analysis of likelihood of lower head failure and ex-vessel fuel coolant interaction energetics for AP1000", Nuclear Engineering and Design, Vol. 235, No. 15, pp. 1583-1605, 2005.

13. Jung J., An S. M., Ha K. S., Kim H. Y., "Evaluation of heat-flux distribution at the inner and outer reactor vessel walls under the in-vessel retention through external reactor vessel cooling condition", Nuclear Engineering and Technology, Vol. 47, No.1, pp. 66-73, 2015.

14. Jeong Y. H., Chang S. H., Baek W. P., "CHF experiments on the reactor vessel wall using a 2D slice test section", Proceedings of the tenth international topical meeting on nuclear reactor thermal hydraulics, pp. 1CD-ROM, Republic of Korea, 2003.
15. Jin Y., Xu W., Liu X., Cheng X., "In- and exvessel coupled analysis of IVR-ERVC phenomenon for large scale PWR", Annals of Nuclear Energy, Vol. 80, pp. 322-337, 2015.

16. Knudson D., Rempe J., Condie K. Suh K., Cheung F.-B., Kim S.-B, "Late-phase melt conditions affecting the potential for in-vessel retention in high power reactors", Nuclear Engineering and Design, Vol. 230, No.1, pp. 133-150, 2004.

17. "In-Vessel Melt Retention (IVMR) Analysis of a VVER-1000 NPP”, EU JRC (Joint Research Centre), Technical Report, 2016.

18. Filippov A.S., Kamenskaya D.D., Moiseenko, E.V., "The development of the heat transfer model in a stratified corium pool for simulation of severe accidents at NPP by SOCRAT/HEFEST", Energy, Vol. 5, pp.108-128, 2013.

19. Filippov A.S., Tarasov V.I. "Simulation of COPO II Lo experiments on natural convection of heat generating liquid at high Rayleigh numbers", Journal of Engineering Thermophysics, Vol. 2, 2014.

20. Ozrin V.D., Tarasov V.I., Filippov A.S., Moiseenko E.V., Tarasov O.V. "Distribution of fission product residual decay heat in stratified core melt of LWR and its influence on sidewall heat flux", Nuclear Engineering and Design, Vol. 261, pp. 107-115, 2013. 